\title{
The Effects of Computer-assisted L1 and L2 Textual and Audio Glosses on Vocabulary Learning and Reading Comprehension across Different Learning Styles
}

\author{
Mojtaba Tadayonifar ${ }^{1}$, Mahnaz Entezari $^{2}$, Mohammadreza Valizadeh $^{3}$ \\ ${ }^{1}$ Victoria University of Wellington, New Zealand \\ ${ }^{2}$ Payame Noor University, Iran \\ ${ }^{3}$ Cappadocia University, Turkey
}

\begin{abstract}
Correspondence concerning this article should be addressed to Mojtaba Tadayonifar, School of Linguistics and Applied Language Studies, Victoria University of Wellington, Wellington, New Zealand. E-mail:mtadayon.253@gmail.com
\end{abstract}

\begin{abstract}
The current study investigated the effects of computer-assisted L1 and L2 textual and audio glosses on vocabulary learning and reading comprehension across various learning styles. Based on the PET test, 30 homogeneous Iranian EFL learners took the VARK questionnaire and were divided into five learning style groups. Twenty-eight words were selected to be glossed in four reading passages. The selected passages, which were glossed in the four different forms of L1 and L2 audio and L1 and L2 textual by creating hyperlinks on the target words, were presented to the participants through a computer screen. All groups underwent all the treatment conditions and then took posttests.Three-way ANOVAs were run to investigate the effects of learning styles, modes, and language, and their two-way and three-way interactions on the performance of EFL learners on the vocabulary and reading comprehension posttests. While no significant differences between language and mode of glosses on the reading comprehension posttest scores were observed, it was revealed that L1 glosses were more beneficial than L2 glosses for vocabulary learning. The study also showed that the textual glosses were more effective than audio glosses for vocabulary learning. The results further displayed significant differences between learning styles on the vocabulary learning and reading comprehension posttest scores.
\end{abstract}

Keywords: computer-assisted glossing, learning styles, VARK questionnaire, vocabulary learning, reading comprehension

\section{Introduction}

The pivotal role that vocabulary plays in developing all the other language skills and successful second language use in ESL and EFL contexts is hardly disputable (e.g., Nation, 2011). Language researchers have proposed extensive reading as an effective way to acquire a large vocabulary repertoire (Pitts, White, \& Krashen, 1989; Waring \& Takaki, 2003). However, exposing learners to a wide range of texts with varying word density, especially lower-level learners, might lead to confusion and frustration rather than learning (Hu \& Nation, 2000; Jiang, 2000). Therefore, an additional support is needed to assist learners cope with these constraints and provide the optimal conditions for L2 vocabulary learning (Choi, 2016). Glossing, which has been described by Nation (2013) as a short definition or a synonym accompanying the text either in the L1 or an L2, can provide this additional support. The noticing hypothesis (Schmidt, 1995), which declared that in order for the input to be processed further,learners' attention should be drawn to it, provides the theoretical basis for glossing. Multimedia glosses, which utilize different gloss modes such as text, sounds, and pictures to present the definition of words, increase learners' engagement with the texts and provide the optimal condition for the learning of vocabulary items. Therefore, the generative theory of multimedia learning (GTML) (Mayer, 2001) and the dual coding theory (Paivio, 1990), which both support meaningful learning through engagement in visual and verbal cognitive processing, further advocate the use of glossing.

When the issue of glossing versus no glossing has been resolved in favor of the glossing condition (Cheng \& Good, 2009; Choi, 2016; Ko, 2012; Watanabe, 1997; Yanguas, 2009; Yoshii, 2006), researchers have tried to consider other features that might have an influence on the efficacy of glosses, like the language used to gloss 
the target words (Choi, 2016; Ko, 2012; Miyasako, 2002; Yoshii, 2006), the types of glossing i.e. single or multiple glosses (Al-Seghayer, 2001; Khezrlou \& Modirkhameneh, 2016; Kost, Fost, \& Lenzini, 1999; Plass, Chun, Mayer, \& Leutner, 1998;Rott, 2005; Sadeghi, Watanabe, 1997; Yanguas, 2009; Yoshii \& Flaitz, 2002), and computer-mediated glosses (e.g. Khezrlou, Ellis, \& Sadeghi, 2017; Türk \& Erçetin, 2012), which provided the opportunity for researchers to consider a combination of factors. Some researchers have attempted to compare the effectiveness of electronic glosses to the traditional glosses (Taylor, 2006; Yousefzadeh, 2011) as well as the learners' attitudes towards computerized glosses (Bowels, 2004; Lenders, 2008). The majority of these studies have revealed that the multimedia gloss groups outperformed the traditional gloss groups and that learners had positive attitudes towards e-glossing (e.g. Lenders, 2008). Thus, the researchers have tried to investigate the effectiveness of multimedia glosses taking into account other factors such as different types of multimedia glosses (Sakar \& Erçetin, 2005; Yanguas, 2009), individual differences like working memory capacity (Varol \& Erçetin, 2019), learning styles (Rassaei, 2017), and proficiency levels (Hu, Vongpumivitch, Chang, \& Liou, 2014). Some other researchers have compared the effectiveness of L1 versus L2 multimedia glosses (Barabadi, Aftab, \& Panahi, 2018; Hu et al., 2014). Recently, some researchers have been interested in finding the best possible place to put the glossed words and compared in-text, marginal, pop-up, or tool-tip glosses (Abuseileek, 2011; Chen, 2016; Lee \& Lee, 2014; Varol \& Erçetin, 2019). Conditions (explicit, incidental, and intentional) and time (interactive vs simultaneous presentation) of gloss presentation have also taken into consideration (Khezrlou, Ellis, \& Sadeghi, 2017; Türk \& Erçetin, 2012).

Presenting glosses in different modes (textual vs. auditory) has also sparked some studies. Sadeghi and Ahmadi (2012) explored the effects of textual glosses, CALL audio glosses, and CALL extended audio glosses (a speaker read the meaning of the target words and provided an example) on learners' reading comprehension. The results showed that the groups exposed to the extended audio glosses outperformed the other groups significantly. Rassaei (2017) also examined the impacts of textual and audio glosses on L2 vocabulary learning. He further investigated the moderating impact of students' perceptual style. The findings indicated that audio glosses were more effective than textual glosses. Moreover, the auditory learners who were exposed to audio glosses showed the greatest amount of vocabulary learning. In a recent meta-analysis and by taking into account 42 related studies in this area, Yanagisawa, Webb, and Uchihara (2020) investigated the moderating effects of gloss format (type, language, and mode), text characteristics (comprehensibility, target word percentage, text type, CALL use, and whether the texts targeted L2 learners or native speakers), and learner characteristics (proficiency) on L2 vocabulary learning from reading. The results revealed that L1 glosses led to better learning than L2 glosses. They further found no significant difference among textual, pictorial, and auditory gloss modes.

As mentioned above, in computer-mediated glossing, many factors have been considered, but the relationship between learning styles, as one of the most important dimensions of individual differences, and multimedia gloss modes needs to be investigated further as there is a lack of studies in this regard. Oxford (2003) defined learning styles as general approaches that learners use in the learning of any subjects, including language. While some researchers found that the match between learning and teaching styles could enhance students' motivation and achievements (Lovelace, 2005; Thomson, Watt, \& Liukkonen, 2015), others believed that there is quite a bit of disconfirming evidence that learning styles in any of their various guises provide a foundation for teaching (Hussman \& O’Loughlin, 2018; Knoll, Otani, Skeel, \& Van Horn, 2017; Willingham, Hughes, \& Dobolyi, 2015). Thus, further research is needed to shed more light on this aspect (Liu \& Todd, 2014). One way to show if tailoring learning and teaching styles improve L2 performance, which might further lead to the corroboration of the learning style hypothesis, is to compare the vocabulary and reading gains of learners with different learning styles following different multimedia glossing conditions that matched or did not match their learning styles. There is only one research paper in this regard. Rassaei (2017) investigated the impacts of matching multimedia glossing (textual and audio) to perceptual styles only on vocabulary learning by presenting just L1 glosses. Therefore, investigating the effects of tailoring glossing to the learners' learning styles by using both L1 and L2 multimedia glosses on vocabulary learning as well as reading comprehension gains may lead to different results. Moreover, he only used visual and auditory styles, but there are more than two learning styles and some people prefer a combination of styles. Based on this classification, Klement (2014) found that the largest group of students consisted of kinesthetic learning style, which was ignored in Rassaei's (2017) study. Thus, a more comprehensive taxonomy of learning styles is required if the relationship between learning styles and multimedia glossing is going to be measured. The VARK learning style classification was utilized to decrease the limitations of Rassaei's (2017) study as it divides the students into four styles, which is 
more representative. Thus, the researchers intended to conduct this study to investigate the effects of computer-assisted L1 and L2 textual and audio glosses on vocabulary learning and reading comprehension considering various learning styles.

\section{Literature Review}

Previous research has shown that providing a form of glossing is effective in improving vocabulary learning. This motivated researchers to delve more deeply into the impacts of other factors which might affect their efficacy. Thus, factors like the language used to gloss the target words, types of glosses, and individual differences in learners' performances were considered. However, the studies in the latter group are limited to one or two studies and further research is needed in this area. In this section, the studies which are more relevant to the current study are discussed.

\section{The Language of Glosses}

The language used to gloss the texts might influence the effectiveness of the glosses. Therefore, some researchers attempted to explore the efficacy of L1, L2, or a combination of L1 and L2 glosses in their studies. For instance, Ko (2012) asked the participants to read materials under three different conditions of no-gloss, L1 gloss, and L2 gloss. Findings showed that there was a significant difference between glossed conditions and nogloss condition on the immediate vocabulary test, but no significant differences between L1 and L2 glosses were found. Choi (2016) explored the effects of L1 and L2 glosses on incidental vocabulary acquisition and lexical representations. The participants read a story under three conditions of L1, L2, or without glosses. Similar to Ko (2012), the results indicated that glossed condition groups performed significantly better than no-gloss condition. It was further revealed that although the L1 and L2 groups did not differ in the immediate recall, the L1 group performed better in the long-term retention. In two recent meta-analyses, Yanagisawa et al. (2020) and Kim, Lee, and Lee (2020) examined the impacts of L1 and L2 glosses on L2 vocabulary learning and reading comprehension. They found that L1 glosses were more effective than L2 glosses.

Cheng and Good (2009) investigated the impacts of three gloss types of L1 plus L2 glosses, L1 in-text, and L1 marginal glosses in comparison with the no-gloss condition on reading comprehension and vocabulary acquisition. The study indicated that L1 glosses helped participants learn new words and review the learned words. The results further showed that the participants in the gloss conditions performed better on the vocabulary recall tests, but the glossing conditions did not affect reading comprehension significantly. However, the study indicated that besides the language of glosses, other factors like proficiency levels could affect gloss efficacy and not all levels of students benefit from L1 glosses. To address this, Hu et al. (2014) analyzed the effects of L1 and L2 e-glosses on incidental vocabulary learning. The participants were divided into four groups based on whether they would receive L1 glosses or L2 glosses first. The results showed that the high-proficiency groups who first received L2 glosses remembered more words on the delayed posttest. The study suggested that both L1 and L2 glosses can be effective, but they should be selected according to the learners' proficiency levels.

The amount of leaner engagement with the L1 and L2 glosses also caught the attention of some researchers. Samian, Foo, and Mohebbi (2016) attempted to explore the effect of giving and receiving marginal L1 glosses on L2 vocabulary learning. The participants were divided into L1 glosses giver, L1 glosses receiver, and no-gloss groups. The giver group was asked to do the reading tasks using a bilingual dictionary, and write down the L1 equivalents. The receiver group was asked to perform the same tasks which included L1 equivalents of the targeted words. The control group had no access to marginal glosses while completing the tasks. The results of the immediate and delayed posttests revealed that both the giver and receiver conditions affected L2 vocabulary learning. Further, the study found that the giver group made the most favorable progress over time. In a similar research study, Rassaei (2020) explored the impact of dynamic and nondynamic glosses on EFL learners' vocabulary knowledge. In the dynamic gloss condition, the participants were presented with a set of short passages that were glossed from the most implicit to the most explicit for each unfamiliar word. In the nondynamic glossing condition, a first language definition for each target word was provided. Similar to Samian et al. (2016) who found the beneficial effects of engaging learners more in the text by using a bilingual dictionary, the results of this study also showed that the dynamic glossing condition was more effective than the nondynamic condition for L2 vocabulary learning. 
In a multimedia environment, Yoshii (2006) investigated how adding a pictorial cue to the L1 and L2 glosses affected vocabulary learning. There were four glossing conditions: L1 text only, L2 text only, L1 text plus pictorial gloss, and L2 text plus pictorial gloss conditions. Results from the data analysis showed that the difference between picture and no-picture gloss conditions was significant, but the difference between L1 and L2 glosses was not. Rouhi and Mohebbi (2012) also investigated the impact of computer-mediated L1 and L2 glosses on L2 vocabulary learning. The participants of the experimental groups read the passages of their textbook for six sessions. Then, they took the immediate posttest and the delayed posttest. Findings showed the superiority of the glosses groups (L1 and L2) over the control group. Further, the L1 glosses were more effective than the L2 glosses on the posttests. The results suggested that the L1 can be used as an effective tool to gloss the texts.Barabadi et al. (2018) investigated the impact of L1 and L2 glosses along with computergenerated phonological guidance on vocabulary learning. Contrary to Rouhi and Mohebbi (2012), the results indicated that L1 and L2 glosses assisted with phonological guidance resulted in better performance regardless of the language used to gloss the target words. Recently, Yanagisawa et al. (2020) in a meta-analysis indicated that L1 glosses led to greater learning than L2 glosses. However, they observed no interactions between language, proficiency, and mode of glossing.In a meta-analysis, Taylor (2020) examined the key factors related to how CALL glossing can be effective. The findings showed that CALL glosses could promote L2 text comprehension. The study also indicated that large amounts of CALL glossing may not necessarily lead to L2 reading comprehension. The results further revealed that textual glossing with pictures might be the most effective form of CALL glossing.

The conflicting results obtained from the studies in this category indicate that there could be other factors that influence the effectiveness of glosses to improve vocabulary learning and reading comprehension. Thus, some studies explored the effects of utilizing various gloss types to promote vocabulary learning and reading comprehension.

\section{Utilizing Different Gloss Types}

Following the generative theory of multimedia learning, Plass et al. (1998) exposed English-speaking German learners to a story that was glossed with either visual, verbal, or both visual and verbal annotations. The results showed that learners recalled the words better when they used both types of annotations. Similarly, the results of the study conducted by Kost et al. (1999) and Yoshii and Flaitz (2002) showed that a combination of annotations resulted in better performance. Al-Seghayer (2001) exposed learners to a reading text that was glossed with either printed text definition alone, printed text definition accompanied by video clips, or printed text definition coupled with still pictures. He found that video clips were more effective than still pictures in both production and recognition measurements. Rott (2005) glossed a text with multiple-choice annotations or single-translation glosses. The results indicated that multiple-choice glosses were more facilitative than the single-translation glosses for establishing lexical form-meaning connections. In an attempt to see whether multimedia glosses improve reading comprehension, Sakar and Erçetin (2005) glossed a text with textual, audio, and visual forms. The results showed that the participants preferred visual glosses significantly more than textual and audio glosses. Although the learners showed positive attitudes towards glosses and hypermedia reading in general, a negative relationship between gloss use and reading comprehension was reported. In a similar study, Yanguas (2009) investigated the effects of textual, pictorial, and textual + pictorial multimedia glosses on comprehension and vocabulary learning. The findings showed that multimedia gloss groups performed better than the control group on the vocabulary test, but no significant differences were reported in reading comprehension. Sadeghi et al. (2016) explored how the three gloss types text-picture, text-audio, and text-picture-audio influenced students' vocabulary learning and reading comprehension. The participants were assigned to four learning conditions: intentional, incidental, and explicit instruction operationalized according to either the presence or absence of explicit vocabulary instruction. All of the groups were exposed to all gloss types. The results indicated that text-picture-audio gloss type yielded better scores. The study suggested that the students' performances with different gloss types were condition-specific.

\section{Individual Differences and Glossing}

Some studies attempted to see whether individual differences like intelligence, working memory, educational and proficiency levels, learning styles, etc., had an effect on the efficacy of glosses. For example, Rouhi and Mohebbi (2013) investigated the impacts of pictorial, pictorial + sound, and video glosses on L2 vocabulary 
learning in a multimedia context. They further intended to find whether there was a relationship between learners' high spatial intelligence ability and their ability to take advantage of multimedia glosses in L2 vocabulary learning. The results showed that multimedia glosses could enhance L2 vocabulary learning. They found no significant difference between the high and low spatial ability groups. In a recent study, Varol and Erçetin (2019) investigated the role the type of gloss played in terms of content (lexical vs topical), location (pop-up vs separate window), and working memory capacity in L2 learners' recall and comprehension in e-reading. The participants were assigned to four glossing conditions: separate window topic-level glosses, pop-up window topic-level glosses, separate window lexical glosses, and pop-up window lexical glosses. The results indicated that the impacts of gloss content hinged on the type of task used to measure comprehension while the effect of gloss location was less clear-cut. Working memory capacity played a significant role in comprehension. In a meta-analysis, Ramezanali, Uchihara, and Faez (2020) explored the efficacy of an additional gloss mode on L2 learners' word learning. While the findings indicated that the additional gloss mode had medium and small effects, the impacts of additional gloss modes were affected by a range of variables including learners' characteristics such as educational backgrounds and proficiency levels.

Cheng and Good (2009) mentioned that when evaluating the value of glosses, matching text difficulty to students' language proficiency is gaining importance.Another variable that is important in assessing the value of glosses is learners' learning styles. Matching gloss types to students' learning styles might increase the efficacy of glosses. To provide empirical evidence Rassaei (2017) examined the moderating impact of perceptual styles on L2 vocabulary learning while the learners were exposed to L1 textual, L1 audio, and no-gloss conditions. The study indicated that while both gloss conditions resulted in better vocabulary scores than the no-gloss condition, audio glosses were more effective than textual glosses, especially when they were tailored to the students' preferred styles. In that study, the participants were divided only into visual and auditory styles. However, there are more than two learning styles. For example, based on the classification that there are more than two learning styles and some people prefer a combination of styles, Klement (2014) found that the largest group of students favored the kinesthetic learning style, which was not taken into account in Rassaei's (2017) study. Thus, a more comprehensive taxonomy of learning styles is required if the relationship between learning styles and multimedia glossing is going to be measured. The VARK learning style classification was utilized to decrease the limitations of Rassaei's (2017) study as it divides the students into four styles that are more representative. Thus, the researchers intended to conduct the present study to investigate the effects of computer-assisted L1 and L2 textual and audio glosses on vocabulary learning and reading comprehension across various learning styles.

\section{Aims and Research Questions}

The current study intended to explore the effects of computer-mediated L1 and L2 textual and audio glosses on vocabulary learning and reading comprehension across different learning styles. In the current study, there were four glossing conditions that were used as the treatment conditions: L1 textual glosses, L1 audio glosses, L2 textual glosses, and L2 audio glosses. Therefore, the following research questions were presented.

1. Do the language and modality of glosses and their interactions have an effect on vocabulary learning?

2. Do the language and modality of glosses and their interactions have an effect on reading comprehension?

3. Do the language and modality of glosses and their interactions have an effect on the vocabulary learning of different learning style groups?

4. Do the language and modality of glosses and their interactions have an effect on the reading comprehension of different learning style groups?

\section{Matreials and Methods}

\section{Participants}

An initial sample of 40 students studying English as a foreign language at a private language institute in Iran participated in this study. To select a homogeneous group of students, a Preliminary English Test (PET) was run. PET is an examination targeted at Level B1 (intermediate) in the Council of Europe's Common European Framework of Reference. In this test, candidates who scored between 140 and 152 achieved a "Pass" and 
received a certificate for Level B1, which means intermediate. Therefore, 30 intermediate learners who scored between 140 and $152(\mathrm{M}=145.16, \mathrm{SD}=3.50)$ were selected as the final sample and 10 were excluded. They were excluded if they scored either below or above the criterion. The students were attending English classes in the language institute (twice a week for 90 minutes) where all skills were emphasized. The candidates were verbally announced in class, then information about the aims of the study, time devotion, and using their data for the research purpose was presented through written materials and all of them consented to participate. The participants included 10 males and 20 females between the ages of 19 and 20 .

\section{Instruments}

\section{Vocabulary Knowledge Test}

In order to find the target words, a pilot study was conducted prior to the main study with 10 participants who shared similar backgrounds regarding English learning experience and proficiency. They were asked to read the unglossed version of the reading passages and underline the unknown words. Thirty words were selected based on the pilot study, as more than half of the students identified them as unknown (Bowels, 2004). In addition, 10 words that were considered to be critical for understanding the passages were added to the test by the teacherresearchers. Therefore, a vocabulary knowledge test consisting of 40 words (10 verbs, 17 nouns, and 13 adjectives) was presented to the students prior to the beginning of the treatment sessions. The participants were required to write a definition, or a synonym either in their L1 or L2 to show their knowledge about these words. The decision to include or exclude the words as the final target words was reached in light of the selection criterion adopted in Watanabe (1977) (as cited in Tadayonifar, 2016). This criterion suggested that if a word was familiar to more than 20 percent of the participants, it would not be considered as a target word. Twenty-eight words matched the criterion and were selected as the final target words. They consisted of 14 nouns, 8 adjectives, and 6 verbs (Target words: alternative- authentic- express- a stand- convenient- nightmaretemple- expertise - a trend -an audience - consistent -catchy -to charge- a niche- profits-innovative- a demandsurvive-to target-to be aware of- effective- a takeover- to adapt - to underestimate- empathy - overworkedaspect- to diagnose). Regarding reliability, Cronbach's alpha was satisfactory for the vocabulary knowledge test $(\breve{\alpha}=.82)$.

\section{PET Test}

The Preliminary English Test (PET) is an English language examination supported by Cambridge Assessment English. It is an intermediate-level examination designed for learners mastering the basics of English and having practical language skills for everyday use. The test has reading,writing, listening, and speaking sections. There are two versions of the PET test: PET and PET for Schools. Both versions have the same types of questions. The PET for schools test, which was used in the current study, includes the content of interest to school-age learners. In this study, the PET test was used to select the homogeneous students. It consisted of four sections of listening, speaking, reading, and writing. The reading sections included multiple-choice, matching, and true/ false questions. Regarding reliability, Cronbach's alpha was satisfactory $(\breve{\alpha}=.71)$.

\section{Glossed Reading Passages with Hyperlinks}

As there were four treatment conditions, four reading passages, which were tailored to the participants' proficiency levels, were selected to be glossed based on the Flesch Reading Ease Formula. The first passage 'A Travel Guide' (374 words) received a score of 69.5, the second text 'Innovations in Business' (431 words) got a score of 60, the third one 'Robot Teachers' (348 words) received a score of 62.4, and the last passage entitled 'Social Media Influencers'(448words) got a readability score of 65.1. The passages were chosen from the British Council website, where graded reading passages are available (https://learnenglish.britishcouncil.org/reading). In addition to their suitability for intermediate-level students, the selected passages included authentic and updated content. The authenticity and the freshness of the content could potentially increase the learners' motivation, interest, and engagement in reading, which in turn leads to more attention to the glossed words. A clear definition was chosen as the input used in L2 gloss conditions and an L1 translation of the target words was chosen as L1 gloss conditions.

\section{Fleming's VARK Learning Style Questionnaire}

The VARK learning style inventory, which is a sensory model, was developed by Fleming (2001). The acronym stands for visual, auditory, read/write, and kinesthetic styles. The learning styles include: 1) visual learning 
style (learners with visual learning style mostly learn through observation), 2) auditory learning style (learners with auditory learning style prefer to learn by listening and oral presentation of the contents), 3) read/write learning style (learners with read/write learning style learn by note taking and reading), and 4) kinesthetic learning style (learners with kinesthetic learning style learn through experiments, physical activities, and object manipulation). People's performances in different situations provided the basis for designing the VARK questionnaire items. There are 16 items and each item consisted of four options indicating one of the styles of learning. The preferred learning style of each respondent is the one in which $\mathrm{s} / \mathrm{he}$ has obtained the highest score. If a person obtains similar scores in two or more styles, $\mathrm{s}$ /he will be identified as a learner with mixed learning styles. Javadi Nia et al. (2012) found a test-retest reliability of 0.80 for the VARK questionnaire (cited in Shahrki Pour, Ghoreishinia, Zare, \& Arbabisarjou, 2016). Fitkov-Norris and Yeghiazarian (2015) revealed that the Rasch model fits the majority of the VARK questionnaire data and the sample data supported the internal validity of the four sub-constructs. The dimensionality of VARK using multi-trait and multi-method confirmatory factor analysis was examined and satisfactory reliability estimates were obtained for its subscales, which validated its use as a diagnostic tool (Leite, Svinicki, \& Shi, 2010). This suggested that it could be utilized as a predictor for a person's learning style. In addition to the acceptable reliability and validity measures of VARK obtained in the previous studies, satisfactory test-retest reliability of .79 was also obtained in the current study.

\section{Posttests}

In order to measure the effects of our treatment conditions on vocabulary learning and reading comprehension, eight posttests were designed. Four posttests measured the vocabulary gains and the other four posttests measured reading comprehension. Each vocabulary posttest consisted of seven items in which the participants were required to match the definitions with the related words. The selected words were the same as the target words that were glossed in the passages. Therefore, the maximum score on the vocabulary posttests was seven. Each reading comprehension posttest, which focused on the comprehension of the whole text, consisted of six true or false questions. Although there are problems with this format of reading comprehension tests, their ubiquity in educational settings indicates their practicality for teachers. Even in international standardized tests like IELTS and PET, where stakes are high, true/false comprehension items have kept their place. True/ false questions can be designed to assess surface-level knowledge as well as higher-order thinking. Learners can answer true/false items quickly, which allows test designers to evaluate more items on a test. They are practical test items for teachers as marking is easy and quick. Ebel and Frisbie (1991) argued that such test items have utility for gauging a broad range of verbal knowledge such as the learners' understanding of an event or a process within a passage. Miller (2009) also believed that by avoiding general, negative, and long complete sentences, and including approximately the same number of true/false questions, true/false items could be turned into a valid evaluation format. Thus, in the present study, which utilized classroom research where practicality matters a lot, true/false items were used for their efficiency and practicality. The maximum score in the reading posttests was six. Regarding reliability, Cronbach's alphas were satisfactory (for the vocabulary posttests $\breve{\alpha}=.78$ : for the reading comprehension tests $\breve{\alpha}=.71$ ).

\section{Procedure}

Based on the PET test, which acted as a homogeneity test, a final sample of 30 Iranian EFL learners studying English at an intermediate level in a language institute took part in this study. The VARK questionnaire was administered to determine their learning styles. Based on the questionnaire, five participants were identified as visual learners and seven as auditory style learners. Read/write, kinesthetic, and mixed styles received an equal number of six participants each. Therefore, the participants were divided into five groups based on their learning styles. The study focused on the possible improvement in students' vocabulary and reading comprehension knowledge among the different learning style groups following the treatments. In other words, the study aimed to tailor each learning style to its preferred treatment condition. Through the proficiency and the vocabulary knowledge pretests, the learners' knowledge of vocabulary and reading comprehension were controlled for. Incorporating homogeneous learners in each group enabled the researchers to attribute the potential improvement after the treatments largely to the effects of the treatments. Therefore, no control group was chosen, as the comparison between groups could provide a clearer picture of the effectiveness of each glossing condition for each learning style than comparing their performance before and after the treatment. Next, appropriate materials were developed. As there were four treatment conditions, four reading passages that were tailored to the participants' proficiency levels were selected to be glossed. Out of these 
passages, a total number of 28 words (based on the vocabulary knowledge test) were selected for glossing. The selected passages, which were glossed in four different forms of L1 and L2 audio, and L1 and L2 textual by creating hyperlinks on the target words through Microsoft PowerPoint, were presented to the participants through a computer screen over a period of two months. In the textual glossing conditions, the participants were required to put the cursor on the target words to see the definitions in L2 conditions or translations in L1 conditions. In audio glossing, they were required to click on the hyperlinks to hear the definitions or translations. They were free to refer to the glosses whenever they needed them during the time limit. All of the participants underwent all treatment conditions individually in the classroom setting as part of their class activity. Each session, only one glossed passage was randomly selected and presented to the participants. They were expected to read the glossed passage and then take the vocabulary and the reading comprehension posttests related to that passage after 30 minutes. Thus, in each session two posttests (one to measure vocabulary learning and the other to measure reading gains) were administered. This procedure continued until all glossed passages and their related vocabulary and reading tests were completed. The results were compared to see which glossing condition was more effective for vocabulary learning and reading comprehension. As there was not a separate pretest for measuring the participants' reading comprehension prior to the treatment conditions, the scores from the reading section (true/false part) of the PET pretest were considered as the reading comprehension pretest. As mentioned in the description of the PET pretest, the reading section included multiple-choice, matching, and true/false items.The true/false part consisted of 10 questions and the participants received one mark for each correct answer. The reading comprehension posttest in the current study also consisted of true/ false items. Thus, the nature of true/false questions in the PET reading section is similar to the nature of the reading posttest and comparing the scores extracted from the PET pretest with the posttests could show the effectiveness of the treatment conditions in the present study.In order to see whether the mean differences of the reading comprehension pretest and posttest were significant or not, a paired sample t-test was run. Two three-way ANOVAs were also run to investigate the effects of learning styles, modes, and language, and their two-way and three-way interaction on the performance of EFL learners on the vocabulary and reading comprehension posttests. When the results were significant, post hoc analysis was run to find the exact place of difference.

\section{Results}

\section{The Effects of Glossing Conditions on Vocabulary Learning}

A three-way ANOVA was run to investigate the effect of learning styles, modes, and language, and their twoway and three-way interactions on the performance of EFL learners on the vocabulary tests. Table 1 shows the descriptive statistics of each learning style on the vocabulary posttests.

\section{Table 1}

Descriptive statistics; vocabulary by learning styles

\begin{tabular}{lcccc}
\hline \multirow{2}{*}{ Learning Styles } & Mean & Std. Error & \multicolumn{2}{c}{ 95\% Confidence Interval } \\
\cline { 4 - 5 } & & & Lower Bound & Upper Bound \\
\hline visual & 3.700 & .264 & 3.175 & 4.225 \\
auditory & 5.036 & .224 & 4.592 & 5.479 \\
read/write & 4.792 & .241 & 4.313 & 5.271 \\
kinesthetic & 4.250 & .241 & 3.771 & 4.729 \\
mixed & 4.375 & .241 & 3.896 & 4.854 \\
\hline
\end{tabular}

According to Table 1 , the auditory group $(\mathrm{M}=5.03)$ had the highest mean on vocabulary. This was followed by read/write ( $M=4.79)$, mixed ( $M=4.37)$, kinesthetic $(M=4.25)$, and visual $(M=3.70)$. To check the significance of the observed differences, a three-way ANOVA was conducted. Table 2 displays the results of the three-way ANOVA. 
Table 2

Tests of between-subjects effects; vocabulary by learning styles, mode and language

\begin{tabular}{lcccccc}
\hline \multicolumn{1}{c}{ Source } & Type III Sum of Squares & df & Mean Square & F & Sig. & Partial Eta Squared \\
\hline Learning Styles & 24.677 & 4 & 6.169 & 4.410 & .003 & .150 \\
Mode & 12.995 & 1 & 12.995 & 9.290 & .003 & .085 \\
Language & 6.834 & 1 & 6.834 & 4.885 & .029 & .047 \\
Learning Styles * Mode & 55.601 & 4 & 13.900 & 9.937 & .000 & .284 \\
Learning Styles * Language & 1.125 & 4 & .281 & .201 & .937 & .008 \\
Mode * Language & .128 & 1 & .128 & .092 & .763 & .001 \\
Learning Styles * Mode * Language & 1.344 & 4 & .336 & .240 & .915 & .010 \\
Error & 139.886 & 100 & 1.399 & & & \\
Total & 2643.000 & 120 & & & & \\
\hline
\end{tabular}

The results $\left(\mathrm{F}(4,100)=4.41, \mathrm{p}<.05, \mathrm{p}^{2}=.150\right.$ representing a large effect size $)$ indicated that there were significant differences between the five learning styles' means on vocabulary posttests. Thus, post hoc Scheffe's tests were run to see the exact place of difference. Table 3 shows the results of the post hoc Scheffe's tests.

\section{Table 3}

Post hoc Scheffe's tests; vocabulary by learning styles

\begin{tabular}{|c|c|c|c|c|c|c|}
\hline \multirow{2}{*}{ (I) Learning Styles } & \multirow{2}{*}{ (J) Learning Styles } & \multirow{2}{*}{ Mean Difference (I-J) } & \multirow{2}{*}{ Std. Error } & \multirow{2}{*}{ Sig. } & \multicolumn{2}{|c|}{ 95\% Confidence Interval } \\
\hline & & & & & Lower Bound & Upper Bound \\
\hline \multirow{3}{*}{ read/write } & visual & 1.09 & .358 & .062 & -.03 & 2.22 \\
\hline & kinesthetic & .54 & .341 & .643 & -.53 & 1.61 \\
\hline & mixed & .42 & .341 & .828 & -.65 & 1.49 \\
\hline \multirow{4}{*}{ auditory } & visual & $1.34^{*}$ & .346 & .007 & .25 & 2.42 \\
\hline & $\mathrm{read} / \mathrm{write}$ & .24 & .329 & .968 & -.79 & 1.28 \\
\hline & kinesthetic & .79 & .329 & .231 & -.25 & 1.82 \\
\hline & mixed & .66 & .329 & .407 & -.37 & 1.69 \\
\hline \multirow{2}{*}{ mixed } & visual & .68 & .358 & .474 & -.45 & 1.80 \\
\hline & kinesthetic & .13 & .341 & .998 & -.95 & 1.20 \\
\hline kinesthetic & visual & .55 & .358 & .671 & -.57 & 1.67 \\
\hline
\end{tabular}

Note. ${ }^{*}$ The mean difference is significant at the .05 level.

The results indicated that the auditory group had a significantly higher mean than the visual group $(\mathrm{p}<.05)$. There were not any significant differences between other groups.

Table 4 shows the descriptive statistics of each modality on the vocabulary posttests.

\section{Table 4}

Descriptive statistics; vocabulary by mode

\begin{tabular}{lcccc}
\hline \multirow{2}{*}{ Mode } & \multirow{2}{*}{ Mean } & \multirow{2}{*}{ Std. Error } & \multicolumn{2}{c}{ 95\% Confidence Interval } \\
\cline { 4 - 5 } & & & Lower Bound & Upper Bound \\
\hline Textual & 4.761 & .154 & 4.457 & 5.066 \\
Audio & 4.100 & .154 & 3.795 & 4.404 \\
\hline
\end{tabular}


According to Table 4, there was a mean difference between the textual $(M=4.76)$ and audio $(M=4.10)$ modalities on the vocabulary posttests.To see whether the observed difference was significant, the three-way ANOVA was conducted (Table 2). The results $\left(\mathrm{F}(1,100)=9.29, \mathrm{p}<.05, \mathrm{p}^{2}=.085\right.$ representing a moderate effect size) indicated that the textual mode $(\mathrm{M}=4.76)$ had a significantly higher mean than the audio mode $(\mathrm{M}=4.1)$ on the vocabulary posttests.

Table 5 shows the descriptive statistics of L1 and L2 glosses on the vocabulary posttests.

\section{Table 5}

Descriptive statistics; vocabulary by language

\begin{tabular}{lcccc}
\hline \multirow{2}{*}{ Language } & \multirow{2}{*}{ Mean } & \multirow{2}{*}{ Std. Error } & \multicolumn{2}{c}{ 95\% Confidence Interval } \\
\cline { 4 - 5 } & & & Lower Bound & Upper Bound \\
\hline L1 & 4.670 & .154 & 4.366 & 4.975 \\
L2 & 4.190 & .154 & 3.886 & 4.495 \\
\hline
\end{tabular}

Table 5 showed that there was a mean difference between L1 $(\mathrm{M}=4.67)$ and $\mathrm{L} 2(\mathrm{M}=4.19)$ glosses on the vocabulary tests. To see whether the observed difference was significant, a three-way ANOVA was conducted (Table 2). The results $\left(\mathrm{F}(1,100)=4.88, \mathrm{p}<.05, \mathrm{p}^{2}=.047\right.$ representing a weak effect size) indicated that L1 had a significantly higher mean $(\mathrm{M}=4.67)$ than $\mathrm{L} 2(\mathrm{M}=4.19)$ on the vocabulary posttests.

In this part, the results of two-way and three-way interactions on the performance of EFL learners on the vocabulary posttests will be discussed. The results showed that there was a significant interaction between learning styles and mode $\left(\mathrm{F}(4,100)=9.93, \mathrm{p}<.05, \mathrm{p \eta}^{2}=.284\right.$ representing a large effect size $)$. As displayed in Table 6 and Line Graph 1, visual, read/write, kinesthetic, and mixed learning styles had higher means in the textual mode; while auditory learning style had a higher mean in the audio mode.

\section{Table 6}

Descriptive statistics; interaction between learning styles and mode

\begin{tabular}{|c|c|c|c|c|c|}
\hline \multirow{2}{*}{ Learning Styles } & \multirow{2}{*}{ Mode } & \multirow{2}{*}{ Mean } & \multirow{2}{*}{ Std. Error } & \multicolumn{2}{|c|}{ 95\% Confidence Interval } \\
\hline & & & & Lower Bound & Upper Bound \\
\hline \multirow{2}{*}{ visual } & Textual & 4.200 & .374 & 3.458 & 4.942 \\
\hline & Audio & 3.200 & .374 & 2.458 & 3.942 \\
\hline \multirow{2}{*}{ auditory } & Textual & 4.357 & .316 & 3.730 & 4.984 \\
\hline & Audio & 5.714 & .316 & 5.087 & 6.341 \\
\hline \multirow{2}{*}{ read/write } & Textual & 6.167 & .341 & 5.489 & 6.844 \\
\hline & Audio & 3.417 & .341 & 2.739 & 4.094 \\
\hline \multirow{2}{*}{ kinesthetic } & Textual & 4.500 & .341 & 3.823 & 5.177 \\
\hline & Audio & 4.000 & .341 & 3.323 & 4.677 \\
\hline \multirow{2}{*}{ mixed } & Textual & 4.583 & .341 & 3.906 & 5.261 \\
\hline & Audio & 4.167 & .341 & 3.489 & 4.844 \\
\hline
\end{tabular}




\section{Line Graph 1}

Interaction between learning style and mode; vocabulary test

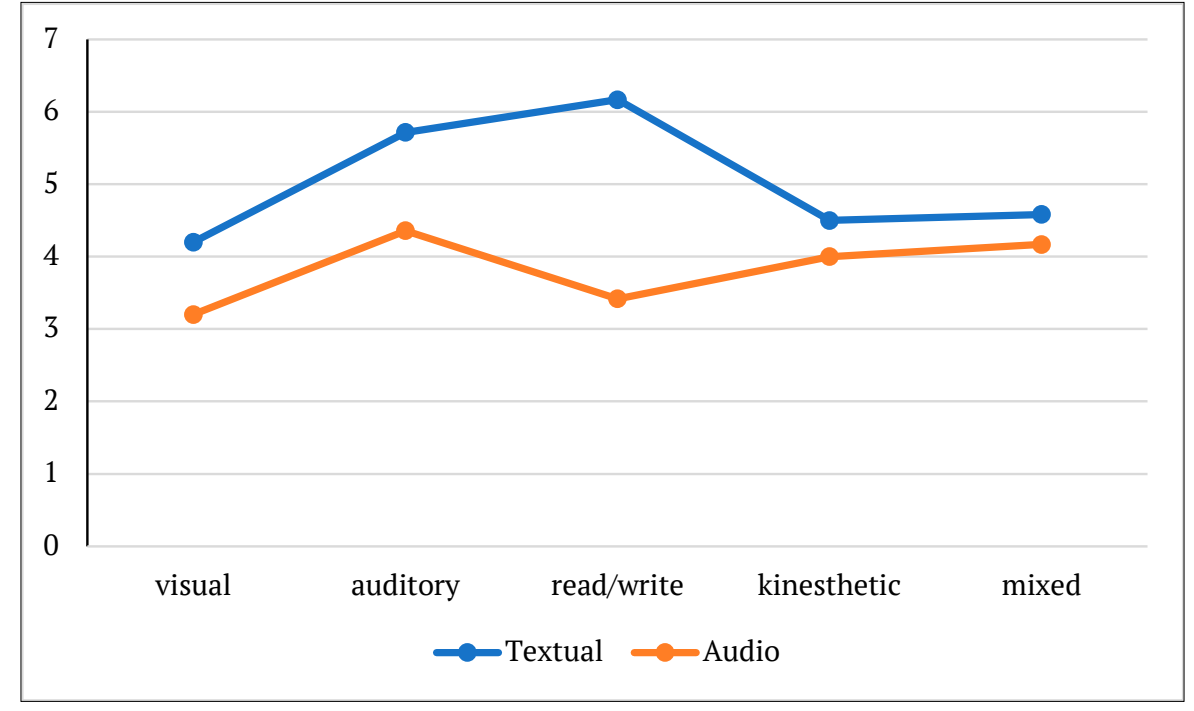

The results further indicated that there was no significant interaction between learning styles and language $(\mathrm{F}$ $(4,100)=.201, \mathrm{p}>.05, \mathrm{p}^{2}=.008$ representing a weak effect size $)$, mode and language $(\mathrm{F}(1,100)=.092, \mathrm{p}>.05$, $\mathrm{p \eta}^{2}=.001$ representing a weak effect size $)$ and learning style, mode, and language $\left(\mathrm{F}(4,100)=.240, \mathrm{p}>.05, \mathrm{p} \eta^{2}\right.$ $=.010$ representing a weak effect size).

\section{The Effects of Glossing Conditions on Reading Comprehension}

The participants' reading comprehension scores before and after exposing them to the glossing conditions were compared. On average, the participants scored higher on the posttests $(M=15.26, S D=3.18)$ than the pretests $(\mathrm{M}=5.93, \mathrm{SD}=1.57)$. Shapiro-Wilk tests indicated that the scores met the normal distribution assumption respectively for the pre and posttests, $\mathrm{W}(30)=0.95, \mathrm{p}=.21), \mathrm{W}(30)=0.95, \mathrm{p}=.51)$. Thus, to explore whether the mean differences of the reading pretests and posttests were significant or not, a paired sample t-test was run. The results indicated that there was a significant difference between the participants' reading comprehension ability before and after the treatment, $t(29)=-13.05, p=.000$.

A three-way ANOVA was run to investigate the effect of learning styles, modes, and language, and their twoway and three-way interactions on the performance of EFL learners on the reading comprehension tests. Table 7 shows the descriptive statistics of each learning style on the reading comprehension posttests.

Table 7

Descriptive statistics; reading by learning styles

\begin{tabular}{lcccc}
\hline \multirow{2}{*}{ Learning Styles } & \multirow{2}{*}{ Mean } & \multirow{2}{*}{ Std. Error } & \multicolumn{2}{c}{ 95\% Confidence Interval } \\
\cline { 4 - 5 } & & & Lower Bound & Upper Bound \\
\hline visual & 3.200 & .285 & 2.634 & 3.766 \\
auditory & 3.929 & .241 & 3.450 & 4.407 \\
read/write & 4.417 & .260 & 3.900 & 4.933 \\
kinesthetic & 3.667 & .260 & 3.150 & 4.183 \\
mixed & 3.583 & .260 & 3.067 & 4.100 \\
\hline
\end{tabular}

According to Table 7, the read/write group had the highest mean on reading $(\mathrm{M}=4.41)$. This was followed by auditory ( $(M=3.92)$, kinesthetic $(M=3.66)$, mixed $(M=3.58)$, and visual $(M=3.20)$. To check the significance of the observed differences, a three-way ANOVA was conducted. The results are presented in Table 8. 
Table 8

Tests of between-subjects effects; reading by learning styles, mode and language

\begin{tabular}{lcccccc}
\hline \multicolumn{1}{c}{ Source } & Type III Sum of Squares & df & Mean Square & F & Sig. & Partial Eta Squared \\
\hline Learning Styles & 18.310 & 4 & 4.577 & 2.811 & .029 & .101 \\
Mode & .002 & 1 & .002 & .001 & .971 & .000 \\
Language & 4.928 & 1 & 4.928 & 3.027 & .085 & .029 \\
Learning Styles * Mode & 20.743 & 4 & 5.186 & 3.185 & .017 & .113 \\
Learning Styles * Language & 6.352 & 4 & 1.588 & .975 & .425 & .038 \\
Mode * Language & 1.044 & 1 & 1.044 & .641 & .425 & .006 \\
Learning Styles * Mode * Language & 18.119 & 4 & 4.530 & 2.782 & .031 & .100 \\
Error & 162.810 & 100 & 1.628 & & & \\
Total & $\mathbf{1 9 5 0 . 0 0 0}$ & $\mathbf{1 2 0}$ & & & & \\
\hline
\end{tabular}

The results $\left(\mathrm{F}(4,100)=2.81, \mathrm{p}<.05, \mathrm{p \eta}^{2}=.101\right.$ representing a moderate effect size $)$ indicated that there were significant differences between the five learning styles' means on the reading posttests.To see which styles had significant differences, post hoc Scheffe's tests were conducted. The results are presented in Table 9.

Table 9

Post hoc Scheffe's tests; reading by learning styles

\begin{tabular}{|c|c|c|c|c|c|c|}
\hline \multirow{2}{*}{ (I) Learning Styles } & \multirow{2}{*}{ (J) Learning Styles } & \multirow{2}{*}{ Mean Difference (I-J) } & \multirow{2}{*}{ Std. Error } & \multirow{2}{*}{ Sig. } & \multicolumn{2}{|c|}{ 95\% Confidence Interval } \\
\hline & & & & & Lower Bound & Upper Bound \\
\hline \multirow{3}{*}{ auditory } & visual & .73 & .374 & .438 & -.44 & 1.90 \\
\hline & kinesthetic & .26 & .355 & .969 & -.85 & 1.38 \\
\hline & mixed & .35 & .355 & .917 & -.77 & 1.46 \\
\hline \multirow{4}{*}{ read/write } & visual & $1.22^{*}$ & .386 & .049 & .00 & 2.43 \\
\hline & auditory & .49 & .355 & .756 & -.63 & 1.60 \\
\hline & kinesthetic & .75 & .368 & .392 & -.41 & 1.91 \\
\hline & mixed & .83 & .368 & .283 & -.32 & 1.99 \\
\hline \multirow{2}{*}{ kinesthetic } & visual & .47 & .386 & .833 & -.75 & 1.68 \\
\hline & mixed & .08 & .368 & 1.000 & -1.07 & 1.24 \\
\hline mixed & visual & .38 & .386 & .911 & -.83 & 1.60 \\
\hline
\end{tabular}

Note.*The mean difference is significant at the .05 level.

The results indicated that read/write group had a significantly higher mean than the visual group ( $<<.05)$. There were not any significant differences between the other groups.

Table 10 shows the descriptive statistics of each modality on the reading comprehension posttests.

Table 10

Descriptive statistics; reading by mode

\begin{tabular}{lcccc}
\hline \multirow{2}{*}{ Mode } & \multirow{2}{*}{ Mean } & \multirow{2}{*}{ Std. Error } & \multicolumn{2}{c}{ 95\% Confidence Interval } \\
\cline { 4 - 5 } & & & Lower Bound & Upper Bound \\
\hline Textual & 3.755 & .166 & 3.426 & 4.083 \\
Audio & 3.763 & .166 & 3.435 & 4.092 \\
\hline
\end{tabular}

Table 10 showed that there was a mean difference between the textual $(M=3.75)$ and audio $(M=3.76)$ modalities on the reading tests.To see whether the observed difference was significant, the three-way ANOVA was 
conducted (Table 8). The results $\left(\mathrm{F}(1,100)=.001, \mathrm{p}>.05, \mathrm{p} \eta^{2}=.000\right.$ representing a weak effect size $)$ indicated that there was no significant difference between the textual and auditory groups' means on the reading posttests.

Table 11 shows the descriptive statistics of L1 and L2 glosses on the reading comprehension posttests.

\section{Table 11}

Descriptive statistics; reading by language

\begin{tabular}{lcccc}
\hline \multirow{2}{*}{ Language } & \multirow{2}{*}{ Mean } & \multirow{2}{*}{ Std. Error } & \multicolumn{2}{c}{ 95\% Confidence Interval } \\
\cline { 4 - 5 } & & & Lower Bound & Upper Bound \\
\hline L1 & 3.555 & .166 & 3.227 & 3.884 \\
L2 & 3.963 & .166 & 3.634 & 4.292 \\
\hline
\end{tabular}

Table 11 showed that there was a difference between the means of the $\mathrm{L} 1(\mathrm{M}=3.55)$ and $\mathrm{L} 2(\mathrm{M}=3.96)$ glosses on the reading test. To see whether the observed difference was significant, the three-way ANOVA was conducted (Table 8). The results $\left(\mathrm{F}(1,100)=3.02, \mathrm{p}>.05, \mathrm{p} \eta^{2}=.029\right.$ representing a weak effect size) indicated that there was no significant difference between the L1 and L2 groups' means on the reading posttests.

In this part, the results of two-way and three-way interactions on the performance of EFL learners on the reading comprehension posttests will be discussed. The results showed a significant interaction between learning styles and mode $\left(\mathrm{F}(4,100)=3.18, \mathrm{p}<.05, \mathrm{p \eta}^{2}=.113\right.$ representing a moderate effect size $)$. As displayed in Table 12 and Line Graph 2, visual, auditory and mixed learning styles had higher means on the audio mode; while read/write had a higher mean in the textual mode. Kinesthetic had equal means in the audio and textual modes.

\section{Table 12}

Descriptive statistics; interaction between learning styles and mode

\begin{tabular}{|c|c|c|c|c|c|}
\hline \multirow{2}{*}{ Learning Styles } & \multirow{2}{*}{ Mode } & \multirow{2}{*}{ Mean } & \multirow{2}{*}{ Std. Error } & \multicolumn{2}{|c|}{ 95\% Confidence Interval } \\
\hline & & & & Lower Bound & Upper Bound \\
\hline \multirow{2}{*}{ visual } & Textual & 3.000 & .403 & 2.199 & 3.801 \\
\hline & Audio & 3.400 & .403 & 2.599 & 4.201 \\
\hline \multirow{2}{*}{ auditory } & Textual & 3.357 & .341 & 2.681 & 4.034 \\
\hline & Audio & 4.500 & .341 & 3.823 & 5.177 \\
\hline \multirow{2}{*}{ read/write } & Textual & 5.083 & .368 & 4.353 & 5.814 \\
\hline & Audio & 3.750 & .368 & 3.019 & 4.481 \\
\hline \multirow{2}{*}{ kinesthetic } & Textual & 3.667 & .368 & 2.936 & 4.397 \\
\hline & Audio & 3.667 & .368 & 2.936 & 4.397 \\
\hline \multirow{2}{*}{ mixed } & Textual & 3.667 & .368 & 2.936 & 4.397 \\
\hline & Audio & 3.500 & .368 & 2.769 & 4.231 \\
\hline
\end{tabular}




\section{Line Graph 2}

Interaction between learning style and mode; reading test

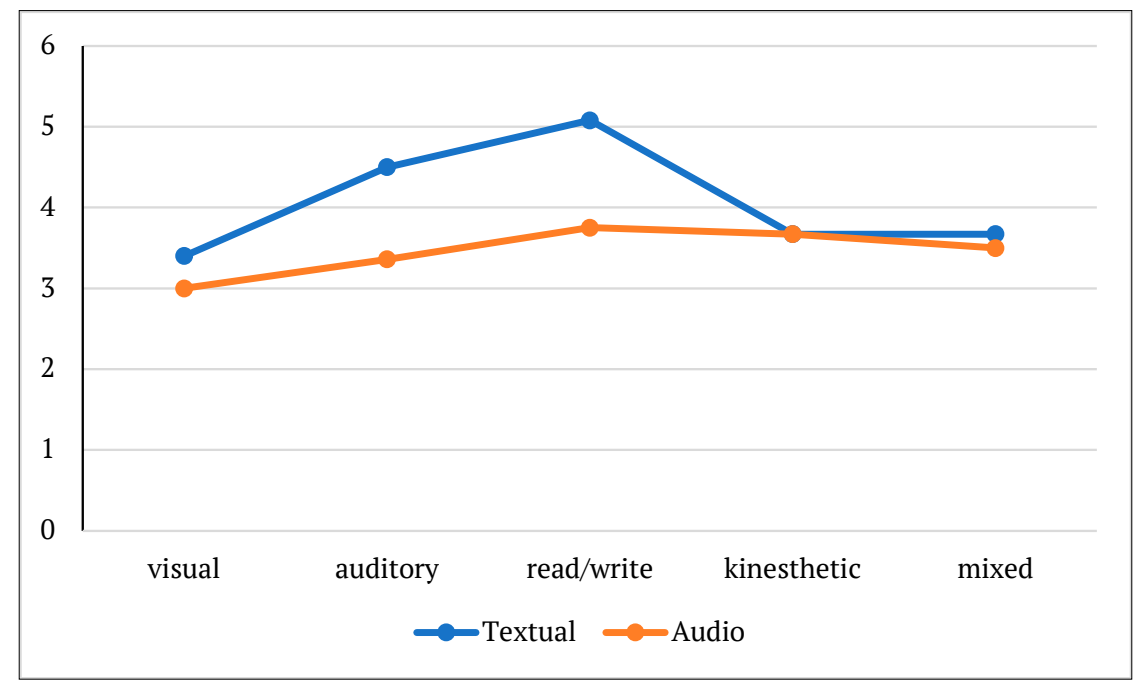

The results further indicated that there was a significant three-way interaction between learning style, mode, and language $\left(\mathrm{F}(1,100)=2.78, \mathrm{p}<.05, \mathrm{p \eta}^{2}=.100\right.$ representing a moderate effect size $)$. As displayed in Table 13 and Line Graph 3, visual, auditory, and read/write learning styles had fairly close means on textual L1 and L2; however, L2 showed a higher mean for kinesthetic and mixed learning styles. A reverse pattern can be seen for the audio mode. Whereas visual and auditory had higher means on L1, read/write, kinesthetic, and mixed had a slightly higher mean on L2.

\section{Table 13}

Descriptive statistics; interaction between learning style, mode, and language

\begin{tabular}{|c|c|c|c|c|c|c|}
\hline \multirow{2}{*}{ Learning Styles } & \multirow{2}{*}{ Mode } & \multirow{2}{*}{ Language } & \multirow{2}{*}{ Mean } & \multirow{2}{*}{ Std. Error } & \multicolumn{2}{|c|}{ 95\% Confidence Interval } \\
\hline & & & & & Lower Bound & Upper Bound \\
\hline \multirow{4}{*}{ visual } & \multirow{2}{*}{ Textual } & L1 & 3.000 & .571 & 1.868 & 4.132 \\
\hline & & L2 & 3.000 & .571 & 1.868 & 4.132 \\
\hline & \multirow{2}{*}{ Audio } & L1 & 2.600 & .571 & 1.468 & 3.732 \\
\hline & & L2 & 4.200 & .571 & 3.068 & 5.332 \\
\hline \multirow{4}{*}{ auditory } & \multirow{2}{*}{ Textual } & L1 & 3.286 & .482 & 2.329 & 4.243 \\
\hline & & L2 & 3.429 & .482 & 2.472 & 4.385 \\
\hline & \multirow{2}{*}{ Audio } & L1 & 4.000 & .482 & 3.043 & 4.957 \\
\hline & & L2 & 5.000 & .482 & 4.043 & 5.957 \\
\hline \multirow{4}{*}{ read/write } & \multirow{2}{*}{ Textual } & L1 & 5.333 & .521 & 4.300 & 6.367 \\
\hline & & L2 & 4.833 & .521 & 3.800 & 5.867 \\
\hline & \multirow{2}{*}{ Audio } & L1 & 4.000 & .521 & 2.967 & 5.033 \\
\hline & & L2 & 3.500 & .521 & 2.467 & 4.533 \\
\hline \multirow{4}{*}{ kinesthetic } & \multirow{2}{*}{ Textual } & L1 & 3.000 & .521 & 1.967 & 4.033 \\
\hline & & L2 & 4.333 & .521 & 3.300 & 5.367 \\
\hline & \multirow{2}{*}{ Audio } & L1 & 3.833 & .521 & 2.800 & 4.867 \\
\hline & & L2 & 3.500 & .521 & 2.467 & 4.533 \\
\hline \multirow{4}{*}{ mixed } & \multirow{2}{*}{ Textual } & L1 & 2.667 & .521 & 1.633 & 3.700 \\
\hline & & L2 & 4.667 & .521 & 3.633 & 5.700 \\
\hline & \multirow{2}{*}{ Audio } & L1 & 3.833 & .521 & 2.800 & 4.867 \\
\hline & & L2 & 3.167 & .521 & 2.133 & 4.200 \\
\hline
\end{tabular}




\section{Line Graph 3}

Interaction between learning style, mode, and language; reading test
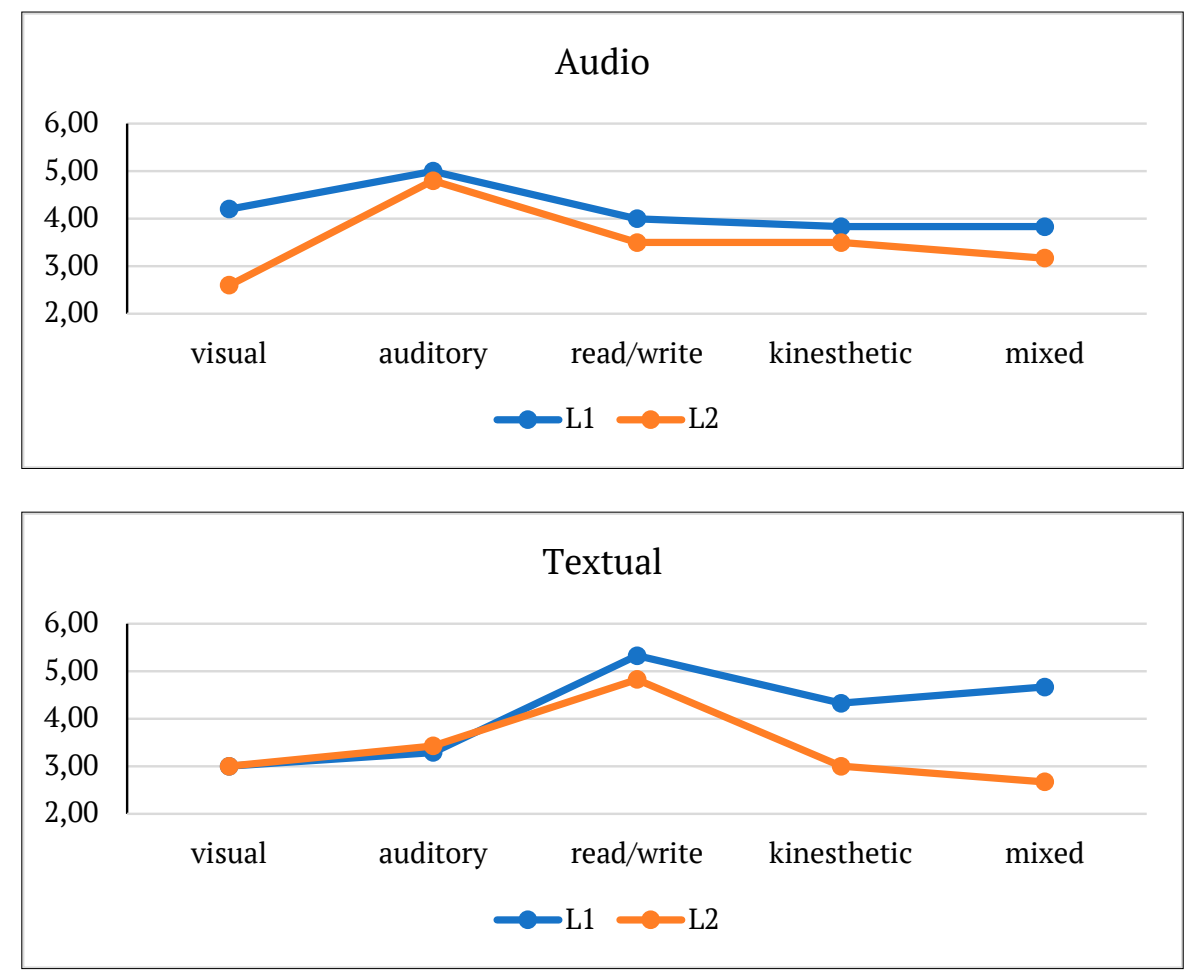

The results also showed that there was no significant interaction between learning styles and language $(\mathrm{F}(4$, $100)=.975, \mathrm{p}>.05, \mathrm{p \eta}^{2}=.038$ representing a weak effect size $)$ and mode and language $(\mathrm{F}(1,100)=.641, \mathrm{p}>.05$, $\mathrm{p \eta}^{2}=.006$ representing a weak effect size).

\section{Discussion}

The present study explored the impacts of glossing mode, language, and learning style on L2 vocabulary learning and reading comprehension. There were two glossing modalities (audio vs textual), five learning styles (visual, auditory, read/write, kinesthetic, and mixed), and two different languages (L1 vs L2). The first and third questions, which aimed to find an ideal glossing condition for vocabulary learning, are discussed together.

In the first research question, the researchers intended to explore the language of glosses as well as the modality through which they presented the glosses and their impacts on vocabulary learning. In line with previous studies (Cheng \& Good, 2009; Choi, 2016; Kim et al., 2020; Rouhi \& Mohebbi, 2012; Yanagisawa et al., 2020), the results revealed that L1 glosses were more beneficial than L2 glosses for vocabulary learning. The study further revealed that textual glosses were more effective than audio glosses in vocabulary learning. Therefore, the L1 textual glossing condition can be considered the best condition for vocabulary learning. The first speculation from these findings is that L1 glosses (L1 translations) were easier to understand than L2 glosses, especially in the written format. This is because in L2 glosses, the participants were required to comprehend the meaning of words both withinthe text and in the provided glosses. This reached the highest level of difficulty for learners when they were required to listen to an audio definition of the target words in L2. Thus, L2 audio glosses were the most difficult to be comprehended and the least effective glossing condition for vocabulary learning. In other words, texts glossed with the L2 might be above the participants' current proficiency levels. This speculation is in harmony with Cheng and Good (2009), who stated that when evaluating the value of glosses, matching text difficulty to students' language proficiency is important. The second explanation might be related to the difference between the modality of the texts and the glossing conditions. To put it another way, for the audio glossing conditions, the glosses and the texts were different in terms of the 
modality, as it might have interfered with the participants' vocabulary learning through glossing. However, in the textual glossing conditions, the glosses were presented in the same modality with the text. This juxtaposition, which is the primary reason for the effectiveness of glosses, might have helped the participants learn the meaning of the target words more easily. Varol and Erçetin (2019) found working memory capacity played a major role in the comprehension of glossed texts. Thus, another speculation is that in L2 glosses, particularly when they are presented in an audio format, learners' memory capacity might determine the efficacy of the glosses. L2 glosses might be less useful for learners with a low working memory capacity while the same glossing mode can be effective for those with a high working memory. However, as the working memory capacity was not taken into account in the current study, future studies might shed more light on the role of working memory capacity and how it benefits from L1 and L2 audio and textual glosses in multimedia environments. The impact of working memory capacity might also be present when dynamic and nondynamic gloss types are presented to learners. As Samian et al. (2016) and Rassaei (2020) indicated, exposing learners to implicit gloss types could enhance the effectiveness of glosses more than explicit types. The results of the current study are different from these studies in that L1 glosses were found to be more effective than L2 glosses. However, there might be other factors like the working memory capacity of the participants, which can affect gloss usefulness.

This finding is in contrast with Rassaei (2017) who found that audio glosses were more effective than textual glosses. However, it should be noted that in that study, only L1 glosses were used. As mentioned earlier, L2 glosses, particularly in audio mode, would put more pressure on the learners and this would affect their vocabulary learning negatively. There might be another reason for this difference. In Rassaei (2017), the participants were directed to new slides to see the textual glosses. This might have negatively influenced the flow of reading in that mode. In the current study, the participants could see both the text and the glosses at the same time by putting the cursor on the target words. Another reason for this difference is that in Rassaei (2017), the participants were divided into only two perceptual styles (visual and auditory). However, there are more than two learning styles (Klement, 2014) and some learners have mixed learning styles. Thus, presenting various glossing conditions to a group of students who were divided into a more comprehensive and representative categorization based on their learning styles can provide a clearer picture of the true nature of learning style constructs and how they match with instruction.

In the third research question, the researchers intended to find an optimal glossing condition for different learning styles to improve vocabulary learning. The results of the three-way ANOVA showed that there were significant differences between the five learning styles' means on the vocabulary posttests. Post hoc analysis showed that the auditory style had a significantly higher mean than the visual style. A significant interaction between learning styles and mode (auditory vs textual) was also observed. The auditory learning style had a higher mean in the audio mode and other styles had higher mean scores in the textual mode.Thus, the most effective condition for vocabulary learning is when audio glosses are presented to those with auditory learning styles. Previous studies (Johnson, Prior, \& Artuso, 2000; Rassaei, 2015, 2017; Slack \& Norwich, 2007; Tight, 2010) also found that learning styles had a significant moderating impact. This means that when the instructional methods are tailored to the students' learning styles, they would have a better performance. Ramezanali, et al. (2020) further showed that the effects of glosses are affected by learners' characteristics. These findings are also close to Tight (2010) and Taylor (2020) who argued that utilizing multiple modalities might be even more effective than matching individual preferences. That is why the concept of learning styles has remained an important factor in instructional settings for many years. The results of the current study indicated that learning styles can be taken into account in addition to other characteristics like educational backgrounds and proficiency levels.Therefore, the answer to the first and third research questions is that for the visual, read/write, kinesthetic, and mixed styles, L1 textual glossing can be considered the ideal condition, and for the auditory style, the L1 audio condition led to better vocabulary learning scores.

The second and fourth research questions, which dealt with finding an ideal glossing condition for improving reading comprehension, will be discussed together. In the second research question, the researchers intended to explore the optimal language and mode to present the glosses for improving reading comprehension. The results showed that there was no significant difference between the language (L1vs L2) and mode (audio vs textual) of glosses on the reading posttests.As a result, it can be stated that creating different glossing conditions did not lead to significant differences among the participants on their reading comprehension posttests scores. The results of this part are in line with Cheng and Good (2009) who found that creating 
different glossing conditions did not affect reading comprehension positively. The use of glosses in Sakar and Erçetin (2005) and multimedia glosses in Yanguas (2009) also did not lead to the improvement of reading comprehension. One reason for the non-significant effect of glossing conditions on reading comprehension could be that while learners were involved in the reading process, they paid less attention to the glossed words in either form. It is also possible that when learners looked at the glossed words in each glossing condition, they lost track of the ideas within the texts.In other words, the glosses distracted the readers from the text and affected the flow of reading negatively. Another reason for this lack of a relationship might be the nature of the posttests. As Yanagisawa et al. (2020) stated, learning gains might be mediated by test formats. Thus, a different reading comprehension test might lead to different results. In the fourth research question, the researchers aimed to find an optimal glossing condition for different learning styles to improve reading comprehension. The results of the three-way ANOVA revealed that there were significant differences between the five learning styles' means on the reading comprehension posttests. This confirmed the hypothesis that tailoring instruction to learning styles improves learning. Husmann and O'Loughlin (2018) reported that as learners' performances were not correlated with their learning styles, the conventional wisdom concerning learning styles should be abandoned by educators and students. However, as the results of the current study revealed, learning styles can be considered an important factor in assessing the efficacy of educational treatments, but different contexts might lead to different results and factors like the subject matter under investigation and the way learning styles have been identified should be considered.

\section{Conclusion}

The objective of this study was to explore the effects of computer-mediated L1 and L2 textual and audio glosses on vocabulary learning and reading comprehension across different learning styles. In other words, the present study aimed to tailor the perceptual styles to glossing conditions. The research questions were successfully answered according to the results. The findings of this study indicated that with regard to vocabulary learning, L1 textual was the most effective glossing condition. It was further understood that despite the effectiveness of this condition for the visual, read/write, kinesthetic, and mixed styles, the L1 audio glossing condition was more effective for the auditory style. The conclusion that can be drawn is that tailoring glossing conditions to preferred learning styles can be effective. The study further indicated that while there was no significant difference between the language (L1vs L2) and mode (audio vs textual) of glosses, significant differences between the learning styles were observed on the reading comprehension posttest scores.

\section{Implications and Limitations}

The findings of the current study have some implications for material developers, learners, and teachers. The results suggested tailoring conditions to learning styles. Therefore, material developers should provide a wide range of glossed passages that suit different learners with different styles. They should also take into account the learners' L1, as the results showed the positive role of L1 in glossing conditions for vocabulary learning. With the increase in the use of technology in language classrooms, teachers can incorporate both audio and textual gloss conditions for improving vocabulary learning based on their preferred learning styles. Another implication for teachers is that they can confidently use the students' L1 to gloss the target words as many studies on glossing have shown the positive role of the L1. Learners can take advantage of the results of the current study in several ways. Learners should be more aware of their likes and dislikes in the learning process. In other words, they should recognize the effective ways in which they learn more efficiently. One of the ways they can do this is to understand their preferred style of learning and ask their teachers to provide the right materials for their specific styles. The results of this study showed that textual glosses suit read/write style and audio glosses suit auditory style. Thus, it is recommended that learners of these styles should look for these conditions if they want to learn vocabulary better.

There were some limitations in this study. The first limitation is about the participants, who consisted of just 30 intermediate learners with the same L1 due to practicality issues. Moreover, for conducting an experimental study, 30 participants might not be enough to yield generalizable results. Therefore, the results should be interpreted with caution. Conducting the same study with a larger number of participants who have different proficiency levels and different L1s could shed more light on the effectiveness of glossing conditions. The second important limitation is the lack of a control group. In the present study, a control group was not selected 
as the focus was on tailoring treatment conditions to learning styles. In so doing, the researchers used both proficiency and vocabulary knowledge pretests to ensure the homogeneity of the participants before exposing them to the experimental treatments. However, in order to provide a broader understanding of the effects of different glossing conditions on learners' vocabulary and reading comprehension knowledge, including a control group could help. The third limitation is that the researchers only conducted an immediate posttest to investigate the effects of glossing conditions on reading comprehension and vocabulary learning. Therefore, a topic like 'the immediate and long-term effects of computer-mediated L1 and L2 textual and audio glosses on vocabulary learning and reading comprehension' is recommended. The fourth limitation is related to the reading comprehension pretest. Although the PET test included a reading section and was conducted prior to the study, future studies could use a reading comprehension pretest to evaluate the reading comprehension ability of the participants separately. Additionally, the reading comprehension posttest consisted only of true/ false questions, which might raise doubts about the value of such items for measuring reading comprehension. The current project was conducted in a classroom setting and the materials were part of the class activities. Therefore, a complete counterbalancing of the treatment conditions was not possible. Although the researchers included target verbs, nouns, and adjectives in all of the conditions to ensure the same level of difficulty across the conditions, the order of exposing participants to the conditions might have influenced the final outcome. Therefore, the final limitation is related to counterbalancing. Future studies can take this into account to reduce the order effects.

\section{Conflicts of interest}

The authors declare that they have no conflicts of interest.

\section{References}

Abuseileek, A. (2011). Hypermedia annotation presentation: The effect of location and type on the EFL learners' achievement in reading comprehension and vocabulary acquisition. Computer \& Education, 57(1), 12811291. https://doi.org/10.1016/j.compedu.2011.01.011

Al-Seghayer, K. (2001). The effect of multimedia annotation modes on L2 vocabulary acquisition: A comparative study. Language Learning \& Technology, 5(1), 202- 232.

Barabadi, E., Aftab, A., \& Panahi, A., (2018). The relative impact of L1 and L2 glosses along with computergenerated phonological guidance on EFL learners' vocabulary learning. Cogent Education, 5 (1). https://doi. org/10.1080/2331186X.2018.1483048

Bowels, M., A. (2004). L2 Glossing: To CALL or not to CALL.Hispania 87 (3), 541-552.

Chen, I. (2016). Hypertext glosses for foreign language reading comprehension and vocabulary acquisition: effects of assessment methods, Computer Assisted Language Learning, 29(2), 413-426. https://doi.org/10.108 $0 / 09588221.2014 .983935$

Cheng, Y., \& Good, R. L. (2009). Glosses: effects on EFL learners' reading comprehension and vocabulary retention. Reading in a Foreign Language, 21(2), 119-142.

Choi, S. (2016). Effect of L1 and L2 glosses on incidental vocabulary acquisition and lexical representations. Learning and Individual Differences, 45, 137-143. http://dx.doi.org/10.1016/j.lindif.2015.11.018

Ebel, R. L., \& Frisbie, D. A. (1991). Essentials of educational measurement. Prentice Hall.

Fitkov-Norris, E., Yeghiazarian, A. (2015). Validation of VARK learning modalities questionnaire using Rasch analysis. Journal of Physics Conference Series, 588(1), 1-7. https://doi.org/10.1088/1742-6596/588/1/012048

Fleming, N. D. (2001). Teaching and learning styles: VARK strategies. N.D. Fleming.

Hu, H. C., \& Nation, P. (2000). Unknown word density and reading comprehension. Reading in Foreign Language, 13, 403 - 430. https://doi.org/10.26686/wgtn.12560354

Hu, S., Vongpumivitch, V., Chang, J. S., \& Liou, H. C. (2014). The effects of L1 and L2 e-glosses on incidental vocabulary learning of junior high-school English students. ReCALL, 26(1), 80-99. https://doi.org/10.1017/ S0958344013000244

Husmann, P.R., O’Loughlin, V.D. (2018). Another nail in the coffin for learning styles? Disparities among undergraduate anatomy students' study strategies, class performance, and reported VARK Learning styles. Anatomical Sciences Education, 12(1), 6-19. https://doi.org/10.1002/ase.1777

Jiang, N. (2000). Lexical representation and development in a second language. Applied Linguistics, 21, 47-77. 
Johnson, J., Prior, S., \& Artuso, M. (2000). Field dependence as a factor in second language communicative production. Language Learning, 50, 529-567. https://doi.org/10.1111/0023-8333.00137

Khezrlou, S., Ellis, R., \& Sadeghi, K. (2017). Effects of computer-assisted glosses on EFL learners' vocabulary acquisition and reading comprehension in three learning conditions. System, 65, 104-116. https://doi. org/10.1016/j.system.2017.01.009

Kim, H. S., Lee, J. H., \& Lee, H. (2020). The relative effects of L1 and L2 glosses on L2 learning: A meta-analysis. Language Teaching Research, 24(6), 739-742. https://doi.org/10.1177/1362168820981394

Klement, M. (2014). How do my students study? An analysis of students' of educational disciplines favorite learning styles according to VARK classification. Procedia Social and Behavioral Sciences. 132, 384-390. https://doi.org/10.1016/j.sbspro.2014.04.326

Ko, M. H. (2012). Glossing and second language vocabulary learning. TESOL Quarterly, 46, 56-79. https://doi. org/10.1002/tesq.3

Knoll, A.R., Otani, H., Skeel, R.L., \& Van Horn, K.R. (2017). Learning style, judgements of learning, and learning of verbal and visual information. British Journal of Psychology 108(3), 544-563. https://doi.org/10.1111/ bjop. 12214

Kost, C. R., Foss, P., \&Lenzini, J. J. (1999). Textual and pictorial glosses: Effectiveness on incidental vocabulary growth when reading in a foreign language. Foreign Language Annals, 32(1), 89-113. https://doi. org/10.1111/j.1944-9720.1999.tb02378.x

Lee, H., \& Lee, J.H. (2014). The effects of electronic glossing types on foreign language vocabulary learning: Different types of format and glossary information. The Asia- Pacific Education Researcher, 24(4), 591601. https://doi.org/10.1007/s40299-014-0204-3

Leite, W., Svinicki, M., \& Shi, Y. (2010). Attempted validation of the scores of the VARK: Learning styles inventory with multitrait-multimethod confirmatory factor analysis models. Educational and Psychological Measurement, 70(2), 323-339. https://doi.org/10.1177\%2F0013164409344507

Lenders, O. (2008). Electronic glossing - is it worth the effort? Computer Assisted Language Learning, 21(5), 457481. https://doi.org/10.1080/09588220802447933.

Liu, Y.T., \& Todd, A.G. (2014). Dual-modality input in repeated reading for foreign language learners with different learning styles. Foreign Language Annals, 47, 684-706. https://doi.org/10.1111/flan.12113

Lovelace, M.K. (2005). Meta-analysis of experimental research based on the Dunn and Dunn model. The Journal of Educational Research, 98, 176-183. https://psycnet.apa.org/doi/10.3200/JOER.98.3.176-183

Mayer,R.E.(2001).Multimedia learning. Cambridge University Press.https://doi.org/10.1017/CBO9781139164603

Miller, M. D., Linn, R. L., Gronlund, N.E. (2009). Measurement and Assessment in Teaching (10 ${ }^{\text {th }}$ ed.). Pearson Education, Inc.

Miyasako, N. (2002). Does text-glossing have any effects on incidental vocabulary learning through reading for Japanese senior high school students? Language Education \& Technology, 39, 1-20. https://doi.org/10.24539/ let.39.0 1

Nation, I. S. P. (2011). Research into practice: Vocabulary. Language Teaching, 44(4), 529-539. https://doi. org/10.1017/S0261444811000267

Nation, I. S. P. (2013). Learning Vocabulary in Another Language (2nd ed.). Cambridge University Press.

Oxford, R.L. (2003). Language learning styles and strategies: Concepts and relationships. International Review of Applied Linguistics in Language Teaching, 41, 271-278. https://doi.org/10.1515/IRAL.2003.012

Paivio, A. (1990). Mental representation: A dual-coding approach. Oxford University Press

Pitts, M., White, H., \& Krashen, S. (1989). Acquiring second language vocabulary through reading: A replication of the Clockwork Orange study using second language acquirers. Reading in a Foreign Language, 5, 271-275

Plass, J. L., Chun, D. M., Mayer, R. E., \& Leutner, D. (1998). Supporting visual and verbal learning preferences in a second language multimedia learning environment. Journal of Educational Psychology, 90(1), 25-36. https:// psycnet.apa.org/doi/10.1037/0022-0663.90.1.25

Ramezanali, N., Uchihara, T., \& Faez, F. (2020). Efficacy of multimodal glossing on second language vocabulary learning: A meta-analysis. TESOL Quarterly, 55(1), 105-133. https://doi.org/10.1002/tesq.579

Rassaei, E. (2015). Recasts, field dependence/independence cognitive style, and L2 development. Language Teaching Research, 19, 499-518. https://doi.org/10.1177\%2F1362168814541713

Rassaei, E. (2017). Computer-mediated textual and audio glosses, perceptual style and L2 vocabulary learning. Language Teaching Research, 22(6), 657-675. https://doi.org/10.1177\%2F1362168817690183

Rassaei, E. (2020). Effects of mobile-mediated dynamic and nondynamic glosses on L2 vocabulary learning: A sociocultural perspective. The Modern Language Journal, 104(1), 284-303. https://doi.org/10.1111/modl.12629

Rott, S. (2005). Processing glosses: A qualitative exploration of how form-meaning connections are established 
and strengthened. Reading in a Foreign Language, 17(2), 95-124.

Rouhi, A., \& Mohebbi, H. (2012). The effect of computer assisted L1 and L2 glosses on L2 vocabulary learning. Journal of Asia TEFL, 9(2), 1-19.

Rouhi, A., \& Mohebbi, H. (2013). Glosses, spatial intelligence, and L2 vocabulary learning in multimedia context. 3L: Language, Linguistics, Literature, 19(2), 75 - 87.

Sadeghi, K., Ahmadi, N. (2012). The effect of gloss type and mode on Iranian EFL learners' reading comprehension. English Language Teaching, 5 (12), 159-188. https://doi.org/10.5539/ELT.V5N12P100

Sadeghi, K., Khezrlou, S., \& Modirkhameneh, S. (2016). Calling Iranian learners of L2 English: Effect of gloss type on lexical retention and reading performance under different learning conditions. Journal of Research in Reading, 39(1), 1- 21. https://doi.org/10.1111/1467-9817.12088.

Sakar, A., \& Ercetin, G. (2005). Effectiveness of hypermedia annotations for foreign language reading. Journal of Computer Assisted Learning, 21(1), 28-38. https://doi.org/10.1111/j.1365-2729.2005.00108.x

Samian, H. V., Foo, T. C. V., \& Mohebbi, H. (2016). The effects of giving and receiving marginal L1 glosses on L2 vocabulary learning by upper secondary learners. English Language Teaching, 9(2), 66-76. https://doi. org/10.5539/elt.v9n2p66.

Schmidt, R. (1995). Consciousness and foreign language learning: A tutorial on attention and awareness in learning. Attention and awareness in foreign language learning, 9, 1-63

Shahrki Pour, M., Ghoreishinia, GH., Zare, S., \& Arbabisarjou, A. (2016). Identification of medical students' learning styles in terms of gender. Global Journal of Health Science, 9(4), 1-76.

Slack, N., \& Norwich, B. (2007). Evaluating the reliability and validity of a learning styles inventory: A classroombased study. Educational Research, 49, 51-63.

Tadayonifar, M. (2016). The effects of text type, text length and text difficulty on vocabulary retention through glossing. The Journal of Language Teaching and Learning, 6(1), 92-104

Taylor, A. (2006). The effects of CALL versus traditional L1 glosses on L2 reading comprehension. Calico journal, 23(2), 309-318. https://doi.org/10.1558/cj.v23i2.309-318

Taylor, A. M. (2020). Technology and reading: The effects of CALL glossing. Psychological Reports, 123(6), 1-23. https://doi.org/10.1177/0033294120954139

Thomson, K., Watt, A., \& Liukkonen, J. (2015). Cognitive style and teaching style influences on the motor skill performance of 11 and 12 year old physical education students. Journal of Physical Education and Sport, 15, 509-517. https://doi.org/10.7752/jpes.2015.03077

Tight, D.G. (2010). Perceptual learning style matching and L2 vocabulary acquisition. Language Learning, 60, 792-833. https://doi.org/10.1111/j.1467-9922.2010.00572.x

Türk, E., \&Erçetin, G. (2012). Effects of interactive versus simultaneous display of multimedia glosses on L2 reading comprehension and incidental vocabulary learning. Computer Assisted Language Learning, 27(1), 1-25, https://doi.org/10.1080/09588221.2012.692384

Varol, B., \& Erçetin, G. (2019). Effects of gloss type, gloss position, and working memory capacity on second language comprehension in electronic reading, Computer Assisted Language Learning, 32 (8), 805-967. https:// doi.org/10.1080/09588221.2019.1643738

Waring, R., \& Takaki, M. (2003). At what rate do learners learn and retain new vocabulary from reading a graded reader? Reading in a Foreign Language, 15, 130-163.

Watanabe, Y. (1997). Input, intake, and retention: Effects of increased processing on incidental learning of foreign language vocabulary. Studies in Second Language Acquisition, 19(3), 287-307. https://doi.org/10.1017/ S027226319700301X

Willingham, D.T., Hughes, E.M., \& Dobolyi, D. G. (2015). The scientific status of learning styles theories. Teaching of Psychology, 42(3), 266-271. https://doi.org/10.1177\%2F0098628315589505

Yanguas, I. (2009). Multimedia glosses and their effects on L2 text comprehension and vocabulary learning. Language Learning \& Technology, 13(2), 48-67.

Yanagisawa, A., Webb, S., \& Uchihara, T. (2020). How do different forms of glossing contribute to L2 vocabulary learning from reading? A meta-regression analysis. Studies in Second Language Acquisition, 42(2), 411438. https://doi.org/10.1017/S0272263119000688

Yoshii, M., \& Flaitz, J. (2002). Second language incidental vocabulary retention: The effect of picture and annotation types. CALICO Journal, 20(1), 33-58. https://doi.org/10.1558/CJ.V20I1.33-58

Yoshii, M. (2006). L1 and L2 glosses: Their effects on incidental vocabulary learning. Language Learning and Technology, 10(3), 85-101.

Yousefzadeh, M. (2011). Computer-based glosses vs. traditional-based glosses and L2 learners vocabulary learning. International Journal on New Trends in Education and Their Implications, 2(3), 99-102. 